\title{
Identification of the responsible proteins for increased selenium bioavailability in the brain of transgenic rats overexpressing selenoprotein $M$
}

\author{
YONA KIM $^{1 *}$, JUN SEO GOO ${ }^{2 *}, \mathrm{IL} \mathrm{YONG} \mathrm{KIM}^{1}$, JI EUN KIM ${ }^{2}$, MOON HWA KWAK $^{2}, \mathrm{JUN} \mathrm{GO}^{2}$, \\ SUNBO SHIM $^{3}$, JIN TAE HONG ${ }^{4}$, DAE YOUN HWANG ${ }^{2}$ and JE KYUNG SEONG ${ }^{1}$
}

\begin{abstract}
${ }^{1}$ Laboratory of Developmental Biology and Genomics, College of Veterinary Medicine, BK21 Program for Veterinary Science, Interdisciplinary Program for Bioinformatics and Program for Cancer Biology, Seoul National University, Seoul 151-742;

${ }^{2}$ Department of Biomaterials Science, College of Natural Resources and Life Science,

Life and Industry Convergence Research Institute, Pusan National University, Miryang, Gyeongsangnam-do 627-706;

${ }^{3}$ Department of Laboratory Animal Resources, National Institute of Food and Drug Safety Evaluation, Korea FDA, Cheongwon, Chungcheongbuk-do 363-700; ${ }^{4}$ College of Pharmacy, Chungbuk National University, Cheongju, Chungcheongbuk-do 361-763, Republic of Korea
\end{abstract}

Received March 25, 2014; Accepted September 9, 2014

DOI: 10.3892/ijmm.2014.1945

\begin{abstract}
The present study was conducted to investigate whether the high antioxidant activity induced by selenium (Sel) treatment and selenoprotein M (SelM) overexpression affected the protein profile of the brain cortex. To accomplish this, the changes in global protein expression were measured in transgenic $(\mathrm{Tg})$ rats expressing human SelM $(\mathrm{CMV} / \mathrm{hSelM})$ and non-Tg rats using two-dimensional electrophoresis (2-DE). The results revealed that: i) CMV/hSelM Tg rats showed a high level of enzyme activity for antioxidant protein in the brain cortex compared to non-Tg rats; ii) the high activity of these enzymes induced a decrease in total antioxidant concentration and $\gamma$-secretase activity in CMV/hSelM Tg rats; iii) five proteins were upregulated and three were downregulated by SelM overexpression; iv) among the five upregulated proteins, two associated with creatine kinase B-type (B-CK) and
\end{abstract}

Correspondence to: Professor Je Kyung Seong, Laboratory of Developmental Biology and Genomics, College of Veterinary Medicine, Seoul National University, 1 Gwanak-Ro, Gwanak-Gu, Seoul 151-742, Republic of Korea

E-mail: snumouse@snu.ac.kr

Professor Dae Youn Hwang, Department of Biomaterials Science, College of Natural Resources and Life Science, Life and Industry Convergence Research Institute, Pusan National University, 50 Cheonghak-ri, Samnangjin-eup, Miryang-si, Gyeongsangnam-do 627-706, Republic of Korea

E-mail: dyhwang@pusan.ac.kr

${ }^{*}$ Contributed equally

Key words: selenoprotein M, transgenic rat, protein profile, antioxidant, selenium
E3 ubiquitin-protein ligase RING1 (RING finger protein 1) were further increased in the two groups following Sel treatment, whereas synaptotagmin-15 (SytXV), eukaryotic translation initiation factor $4 \mathrm{H}(\mathrm{eIF}-4 \mathrm{H})$ and lactate dehydrogenase B (LDH-B) were increased or decreased under the same conditions; v) the three downregulated proteins did not induce a significant change in expression following Sel treatment; and vi) the protein expression level alterations of the two selected spots (B-CK and SytXV) identified by 2-DE were extremely similar to the results from western blot analysis. Overall, the results of the present study provide primary novel biological evidence that new functional protein groups and individual proteins in the brain cortex of CMV/hSelM Tg rats are associated with Sel biology, including the response to Sel treatment and SelM overexpression.

\section{Introduction}

Selenium (Sel) is an ubiquitous trace element in nature that has been shown to be essential to various aspects of human health (1). This trace element has also been shown to be required for normal growth and reproduction during spermatogenesis (2). Furthermore, Sel deficiency induces multiple diseases associated with oxidative damage, such as fatal cardiomyopathy, which is endemic in Keshan (China) (3), and muscular dystrophy in patients subjected to long-term unsupplemented parenteral nutrition (4). It is also well known that vitamin E can partially replace Sel deficiency $(5,6)$. Sel exists naturally in organic (such as selenomethionine and selenocysteine) and inorganic forms (such as selenite, selenate and selenide) (7). However, these compounds require catabolizing into inorganic precursors prior to insertion into proteins, and the rare amino acid selenocysteine (Sec) is essential for the catalytic function of selenoenzymes (8). Sec, which is the 21st proteinogenic amino acid, was not initially recognized in the 
classical genetic code as it is encoded by the UGA 'STOP' codon. For Sec insertion at UGA codons in the translation process, a specific RNA stem-loop structure is required. In eukaryotes, this loop resides in the 3'-untranslated region of the mRNA, known as the Sec-insertion-sequence (9). Sel has also been shown to be an essential part of mammalian enzymes, such as glutathione peroxidase (GPx), thyroid hormone deiodinase and thioredoxin reductase. Thus far, 25 genes encoding selenoproteins in the sequenced human genome have been identified (10). Selenoprotein M (SelM) was first reported as a 0.7-kb cDNA gene that encoded a new selenoprotein identified from the mammalian EST database. This gene has a 145-amino acid open reading frame beginning with an ATG codon in a favorable Kozak context and contains an in-frame TGA as the Sec codon. Furthermore, homologous proteins have been identified in the rat, zebra fish and other vertebrates, and Sec was conserved in these homologs (11). There have also been several functional studies of SelM. For example, the study by Müller et al (12) showed that this protein plays a major role in spicule formation in the demosponge Suberites domuncula. In addition, Hwang et al (13) indicated that SelM plays a suppressive or protective role in the pathology of patients with Alzheimer's disease (AD). However, there have been no studies for whether SelM overexpression could affect the changes in global gene expression in CMV/hSelM transgenic (Tg) rats following Sel treatment.

Sel is maintained at high levels in the brain, even upon prolonged dietary Sel deficiency (14). Changes in Sel concentration in the brain and blood have been detected in AD, Parkinson's disease (PD), multiple sclerosis and brain tumors. Several studies have shown that Sel treatment leads to reduced seizures, improved electroencephalogram recordings (15), protection against the depletion of striatal dopamine (16) and a reduction in the progression of neurodegeneration (17). Furthermore, several selenoproteins have been expressed in the brain. Among these proteins, GPx has been localized in glial cells, and its expression level was significantly upregulated in damaged areas in PD (18). High expression of selenoprotein P (SelP) was also observed in the olfactory bulb, hippocampus and frontal cortex (19). Genetically-engineered models, including Tg and knock-out models, can provide a platform to define the in vivo function of genes and to also study the molecular events responding to environmental changes (20). Previous studies using a knock-out model of SelP showed that it had the important function of Sel delivery into the brain tissue $(21,22)$. Other selenoproteins, including selenoprotein $\mathrm{W}$, thioredoxin reductase, $15-\mathrm{kDa}$ selenoprotein and SelP, have also been detected in the brain. However, numerous questions regarding the roles of these proteins in neuronal function remain.

In the present study, the global change of gene expression affected by SelM overexpression and Sel treatment in the brain cortex was investigated. Two-dimensional electrophoresis (2-DE) analysis showed that eight proteins were significantly changed in $\mathrm{CMV} / \mathrm{hSelM} \mathrm{Tg}$ rats. These results indicated that the information isolated from SelM overexpression and Sel treatment may be useful for studying the association between antioxidant conditions and brain disease, which shows a higher level of oxidative stress condition in specific tissues.

\section{Materials and methods}

Maintenance and identification of CMV/hSelM Tg rats. The $\mathrm{CMV} / \mathrm{hSelM}$ Tg rats used in the study, showing high antioxidant status in various tissues, were developed by microinjection of the $\mathrm{CMV} / \mathrm{hSelM}$ recombinant gene into fertilized rat eggs (13). The animal protocol was reviewed and approved based on the ethical and scientific care procedures of the Korea Food and Drug Administration (KFDA)-Institutional Animal Care and Use Committee. All rats were maintained in an accredited KFDA animal facility in accordance with AAALAC International Animal Care policies (Accredited Unit-KFDA; unit No. 000996). The rats were provided a standard irradiated chow diet (Purina Mills Inc., St. Louis, MO, USA) ad libitum and maintained in a specified pathogen-free state under a strict light cycle (lights on at 06:00 h and off at 18:00 h). All the pedigrees were hemizygous for their transgenes.

Experimental design and Sel treatment. Sodium selenite $\left(\mathrm{NaSeO}_{3}\right)$ purchased from Sigma-Aldrich Co., (St. Louis, MO, USA) was dissolved in distilled water to a final concentration of $0.2 \mu \mathrm{mol} / \mu \mathrm{l}(23,24)$. Ten-week-old rats were randomly divided into two subgroups ( $n=6$ per group). The first subgroup of the CMV/hSelM Tg and non-Tg rat groups each received a comparable volume of distilled water daily via intraperitoneal injection (vehicle-treated CMV/hSelM Tg and non-Tg groups), whereas rats in the second subgroup each received $5 \mu \mathrm{mol} / \mathrm{kg}$ body weight/day of sodium selenite via intraperitoneal injection for three weeks (Sel-treated CMV/hSelM Tg and non-Tg groups). At three weeks after Sel-solution injection, the animals were immediately euthanized using $\mathrm{CO}_{2}$ gas, following which the cortex samples from their brains were prepared and stored in Eppendorf tubes at $-70^{\circ} \mathrm{C}$ until assayed.

Analysis of GPx and superoxide dismutase (SOD) activities and total oxidized products concentration. The levels of GPx and SOD in the brain cortex of CMV/hSelM Tg and non-Tg rats were detected by following the colorimetric assay procedure using Bioxytech SOD-525 and Bioxytech GPx-340 kits (OxisResearch ${ }^{\mathrm{TM}}$, Portland, OR, USA). The level of total oxidized products in the sera of CMV/hSelM Tg and non-Tg rats was detected using a Total Antioxidant Status kit (Randox Laboratories Ltd., Antrim, UK) as previously described (13).

$\gamma$-secretase activity analysis. The $\gamma$-secretase activity was detected with a $\gamma$-Secretase Activity kit (R\&D System Inc., Minneapolis, MN, USA) using the manufacturer's instructions. Initially, cortex tissue was homogenized with a glass homogenizer in cold $1 \mathrm{X}$ extraction buffer to yield a final protein concentration of roughly $0.5-2.0 \mathrm{mg}$. These mixtures were incubated on ice for $10 \mathrm{~min}$, after which they were centrifuged at $10,000 \mathrm{x} \mathrm{g}$ for $1 \mathrm{~min}$ to remove the unbroken fragments. The final supernatants collected from the centrifuged mixture were subsequently used for detection of secretase activity, and this process was carried out in the microplate provided by the manufacturer. To perform the enzyme reaction, $50 \mu \mathrm{l}$ tissue lysate was added to each well, followed by $50 \mu 12 \mathrm{X}$ reaction buffer and $5 \mu \mathrm{l}$ substrate. The microplates were gently mixed and incubated in the dark at $37^{\circ} \mathrm{C}$ for $1-2 \mathrm{~h}$ to induce an enzyme-substrate reaction. Final fluorescence produced by the 
reaction was read on a fluorescent microplate reader using a filter that allowed EDANS excitation at between 335-355 nm.

Sample preparation for 2-DE. Analyses of global protein expression by 2-DE were performed according to the methods established by our laboratory in previous studies (25-27). The cortex samples isolated from the brain were homogenized in liquid nitrogen, following which the homogenized tissues were lysed in buffer [7 M urea, $2 \mathrm{M}$ thiourea, $4 \%$ w/v CHAPS, $40 \mathrm{mM}$ Tris and $100 \mathrm{mM}$ dithioerythritol (DTE)]. The sample mixtures were subsequently centrifuged at $45,000 \times \mathrm{g}$ at $4^{\circ} \mathrm{C}$ for $1 \mathrm{~h}$, after which protein concentrations were determined by the Bradford protein assay (Bio-Rad, Hercules, CA, USA). In this process, a cortex sample was generated from a pool of the six animals in each group. The pooled samples were analyzed three times.

2-DE analysis. One-dimensional isoelectric focusing (IEF) was performed using $24 \mathrm{~cm}$ immobilized $\mathrm{pH}$ gradient (IPG) strips (GE Healthcare, Uppsala, Sweden) in a $\mathrm{pH}$ range of 3.0-10.0 (non-linear). Protein (1-mg) was loaded in a total volume of $450 \mu \mathrm{l}$, following which the samples were diluted with rehydration solution [7 $\mathrm{M}$ urea, $2 \mathrm{M}$ thiourea, $4 \% \mathrm{w} / \mathrm{v}$ CHAPS, $40 \mathrm{mM}$ Tris, $100 \mathrm{mM}$ DTE and 2\% IPG buffer $(\mathrm{pH} 3.0-10.0)$ ]. After rehydration for $13 \mathrm{~h}$, the strips were focused at $30 \mathrm{~V}$ for $2 \mathrm{~h}, 100 \mathrm{~V}$ for $2 \mathrm{~h}, 200 \mathrm{~V}$ for $1 \mathrm{~h}, 500 \mathrm{~V}$ for $1 \mathrm{~h}, 1,000 \mathrm{~V}$ for $1 \mathrm{~h}$ and finally at $8,000 \mathrm{~V}$ for $22 \mathrm{~h}$ to obtain $\sim 100,000 \mathrm{VHr}$ (IPGphor; GE Healthcare). Once IEF was completed, the strips were equilibrated in $6 \mathrm{M}$ urea containing $20 \%$ glycerol, $2 \%$ SDS and $0.01 \%$ bromophenol blue with $10 \mathrm{mM}$ tributyl phosphine. Two-dimensional SDS-PAGE was performed using 8-18\% linear gradient acrylamide gels on an EttanDalt system (GE Healthcare). Proteins were visualized by staining with Coomassie blue G-250 (Bio-Rad).

To analyze changes in protein expression between the types of rats according to SelM level, an average gel representing non-Tg rats was compared to an average gel representing the $\mathrm{CMV} / \mathrm{hSelM} \mathrm{Tg}$ rats. Only the filtered spots exceeding an intensity threshold of a 1.5 or 2-fold increase or decrease between non-Tg and CMV/hSleM Tg rats were studied further, whereas the threshold regulation factor for the significance level was set at $\mathrm{P} \leq 0.05$. Furthermore, any spot showing a significant difference in expression between non-Tg and CMV/hSleM Tg rats was analyzed in all the rats to map changes in expression according to Sel-related factors. Finally, the spots showing significant changes in expression were subsequently identified by mass spectrometry.

Identification of protein spots. The stained gels were scanned with a GS800 densitometer (Bio-Rad) and analyzed using Image master ${ }^{\mathrm{TM}}$ (Swiss Institute of Bioinfomatics, Geneva, Switzerland). The spots were digested using trypsin, following which supernatant peptide mixtures were loaded onto a Poros R2 column (Applied Biosystems, Foster City, CA, USA) that had been washed with the following solutions: i) $70 \%$ acetonitrile in $5 \%$ formic acid; ii) $100 \%$ acetonitrile; and iii) $5 \%$ formic acid. Peptides were eluted using $5 \mu \mathrm{l}$ of $\alpha$-cyano-4-hydroxycinnamic acid and analyzed with a matrix-assisted laser desorption/ionization time-of-flight (MALDI-TOF) mass spectrometer (Voyager
DE-PRO; Applied Biosystems). For protein identification, masses of peptides determined by MALDI-TOF were matched with theoretical peptides in the NCBI (http://www.ncbi.nih. gov/) database using the MASCOT (http://www.matrixscience. com) and ProFound programs (http://prowl.rockefeller.edu).

Western blot analysis. Total proteins prepared from a cortex sample of CMV/hSelM Tg and non-Tg rats were separated by electrophoresis on a 4-20\% SDS-PAGE gel for $3 \mathrm{~h}$ and subsequently transferred to nitrocellulose membranes for $2 \mathrm{~h}$ at $40 \mathrm{~V}$. Each membrane was incubated separately with anti-creatine kinase antibody (Abcam, Cambridge, UK), anti-synaptotagmin antibody (Santa Cruz Biotechnology, Inc., Santa Cruz, CA, USA), and anti-actin (Sigma-Aldrich) antibodies overnight at $4^{\circ} \mathrm{C}$. The membranes were incubated with horseradish peroxidase-conjugated goat anti-rabbit immunoglobulin G (Zymed Laboratories, Inc., South San Francisco, CA, USA) at a 1:1,000 dilution at room temperature for $2 \mathrm{~h}$. The membrane blots were developed using a Chemiluminescence Reagent Plus kit (ECL; Amersham Pharmacia Biotech, Inc., Piscataway, NJ, USA).

Statistical analysis. Tests for significance between vehicleand Sel-treated rats were performed using a one-way analysis of variance test of variance (SPSS for Windows, Release 10.10, Standard Version; SPSS, Inc., Chicago, IL, USA). Tests for significance between CMV/hSelM Tg and non-Tg rats were performed using a post-hoc test (SPSS for Windows, Release 10.10, Standard Version) of variance, and significance levels are provided throughout. All the values are reported as the mean \pm standard deviation. $\mathrm{P}<0.05$ was considered to indicate a statistically significant difference.

\section{Results}

Enhancement of SOD and GPX activity in the brain cortex of CMV/hSelM Tg rats. To confirm whether or not alteration of antioxidative conditions is induced by Sel treatment and SelM overexpression in the cortex region of rat brains, the activity of SOD and GPX was measured in the brain tissue of CMV/hSelM $\mathrm{Tg}$ and non-Tg rats using a detection kit containing a specific substrate. In the vehicle-treated group, SOD/GPX activity in the CMV/hSelM Tg rats showed a higher level of enzyme activity than that of the non-Tg rats, although they showed differing rates of increase (Fig. 1A and C). Following Sel treatment, the activity of these enzymes increased significantly in the $\mathrm{CMV} / \mathrm{hSelM} \mathrm{Tg}$ and non-Tg rats. However, the rate of increase in the $\mathrm{CMV} / \mathrm{hSelM} \mathrm{Tg}$ rats was greater than that of the non-Tg rats (Fig. 1A and C). These results indicate that SelM overexpression and Sel treatment induced an increase of antioxidant protection in the brain cortex from $\mathrm{CMV} / \mathrm{hSelM} \mathrm{Tg}$ rats.

Change in total oxidized products concentration in the brain of CMV/hSelM Tg rats. To determine whether or not enhancement of SOD and GPX activity was accompanied by a decreased level of oxidized products, the concentration of total oxidized products was determined in the serum of CMV/hSelM Tg and non-Tg rats following Sel treatment using an ELISA kit. For the vehicle-treated group, the concentration of total oxidized products at the basal level was significantly lower in the 
A

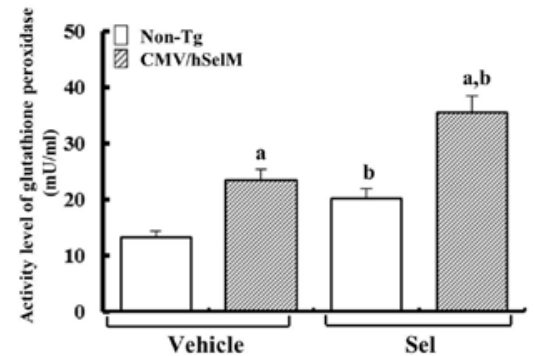

B

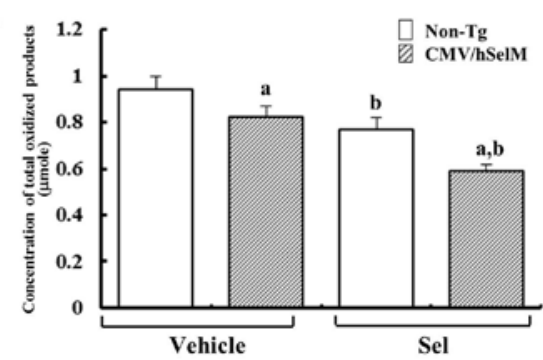

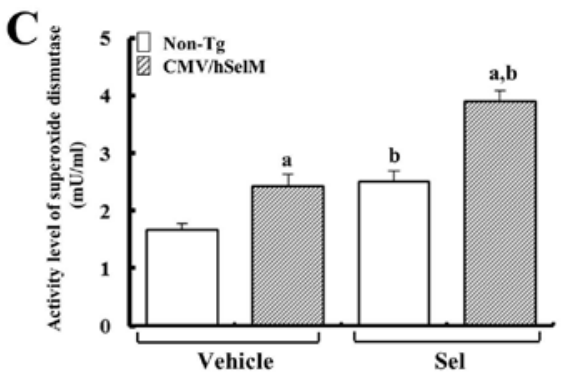

D

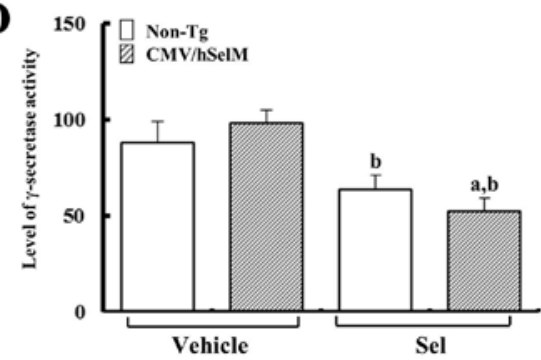

Figure 1. Effects of selenium (Sel) treatment and selenoprotein M (SelM)overexpression on (A) glutathione peroxidase (GPx) activity, (B) superoxide dismutase (SOD) activity, (C) concentration of total oxidized products and (D) $\gamma$-secretase activity in the brain cortex. The brains used in this assay were collected from CMV/hSelM Tg and Non-Tg rats following intraperitoneal injection of sodium selenite (5 $\mu$ mole/kg body weight/day) for three weeks. Enzyme activity and total oxidized products were assayed in six rats per group by ELISA. The data represent the means \pm standard deviation from three replicates. ${ }^{\text {a }}$ Significant difference $(\mathrm{P}<0.05)$ when compared to non-Tg rats; ${ }^{b}$ significant difference $(\mathrm{P}<0.05)$ when compared to the vehicle-treated group.

$\mathrm{CMV} / \mathrm{hSelM} \mathrm{Tg}$ rats compared to the non-Tg rats. Following Sel treatment, these levels decreased simultaneously in the $\mathrm{CMV} / \mathrm{hSelM} \mathrm{Tg}$ and non-Tg rats, although the concentration of total oxidized products in the CMV/hSelM Tg rats was consistently maintained at a low level compared to the non- $\mathrm{Tg}$ rats. In particular, the decreasing rate of total oxidized products concentration in the Sel-treated group was significantly greater compared to the vehicle-treated group (Fig. 1B). These results indicate that the overactivation of SOD and GPX induced by SelM overexpression and Sel treatment contributes to the increase in the functional activity for oxidized products protection in the brain cortex of CMV/hSelM rats.

Change of $\gamma$-secretase activity in the brain cortex of CMV/hSelM $T g$ rats. Furthermore, $\gamma$-secretase plays an important role in the production of $A \beta-42$ peptide in the pathogenesis of $A D(28)$. To investigate the effects of Sel treatment and SelM overexpression on the physiological changes in neurodegenerative pathology, the activity of $\gamma$-secretase, a critical enzyme of $A \beta-42$ peptides production, was measured in the brains of CMV/hSelM Tg and non-Tg rats using a detection kit containing a specific substrate. For the vehicle-treated group, the activity of $\gamma$-secretase in the $\mathrm{CMV} / \mathrm{hSelM} \mathrm{Tg}$ rats was slightly higher compared to non-Tg rats, although this difference was not significant. However, following Sel treatment, these activities were significantly lower in the two groups of rats. Furthermore, the rate of decrease in $\gamma$-secretase activity in the CMV/hSelM Tg rats was higher compared to the non-Tg rats (Fig. 1D). These findings indicate that SelM overexpression and Sel treatment may lead to a decreased incidence of neurodegenerative disease in the brain cortex through the regulation of $\gamma$-secretase activity.

Proteome analysis of total proteins in brain cortex from of CMV/hSelM Tg rats. To characterize the changes in global protein expression in the brain cortex of CMV/hSelM Tg rats in response to the induced bioavailability of Sel treatment and SelM overexpression, whole proteins extracted from the brain cortex of 10-week old CMV/hSelM Tg and non-Tg rats were analyzed on analytic 2-DE gels. Computer analysis of gel images showed good matching in four analytical replicates, including vehicle-treated non-Tg, Sel-treated non-Tg, vehicle-treated $\mathrm{CMV} / \mathrm{hSelM} \mathrm{Tg}$ and Sel-treated CMV/hSelM Tg rats. The 2-DE protein maps of the samples from the four groups are shown in Fig. 2. Approximately 270 spots were detected in one gel from brain cortex. The spots that showed significantly different expression were selected for further analysis. Eight spots were identified as key proteins differentially expressed in four experimental groups. Furthermore, in the vehicle-treated group, eight spots were classified into two groups, including upregulated spots (five spots) and downregulated spots (three spots), according to their expression level in CMV/hSelM $\mathrm{Tg}$ rats. As shown in Table I, the five upregulated proteins included creatine kinase B-type (B-CK), synaptotagmin-15 (SytXV), E3 ubiquitin-protein ligase RING1 (RING1 finger protein 1), lactate dehydrogenase $\mathrm{B}$ (LDH-B) and eukaryotic translation initiation factor $4 \mathrm{H}(\mathrm{eIF}-4 \mathrm{H})$, whereas the three downregulated included centromere protein N (CENP-N), proteasome subunit $\mathrm{K}$ and dihydropyrimidinase-related protein 2 (DRP-2).

Following Sel treatment, the eight spots showed different patterns. The five-upregulated spots were classified into three groups according to their expression pattern. Two neighboring spots in the first group showed a marked increase in response to Sel treatment and were identified as B-CK and RING1 finger protein 1 (Fig. 3). The volume ratio of these two spots was significantly higher in the CMV/hSelM Tg rats compared to non-Tg rats. Following Sel treatment, these volumes were markedly increased in the two groups relative to the vehicle-treated group. Even though the volume of these 


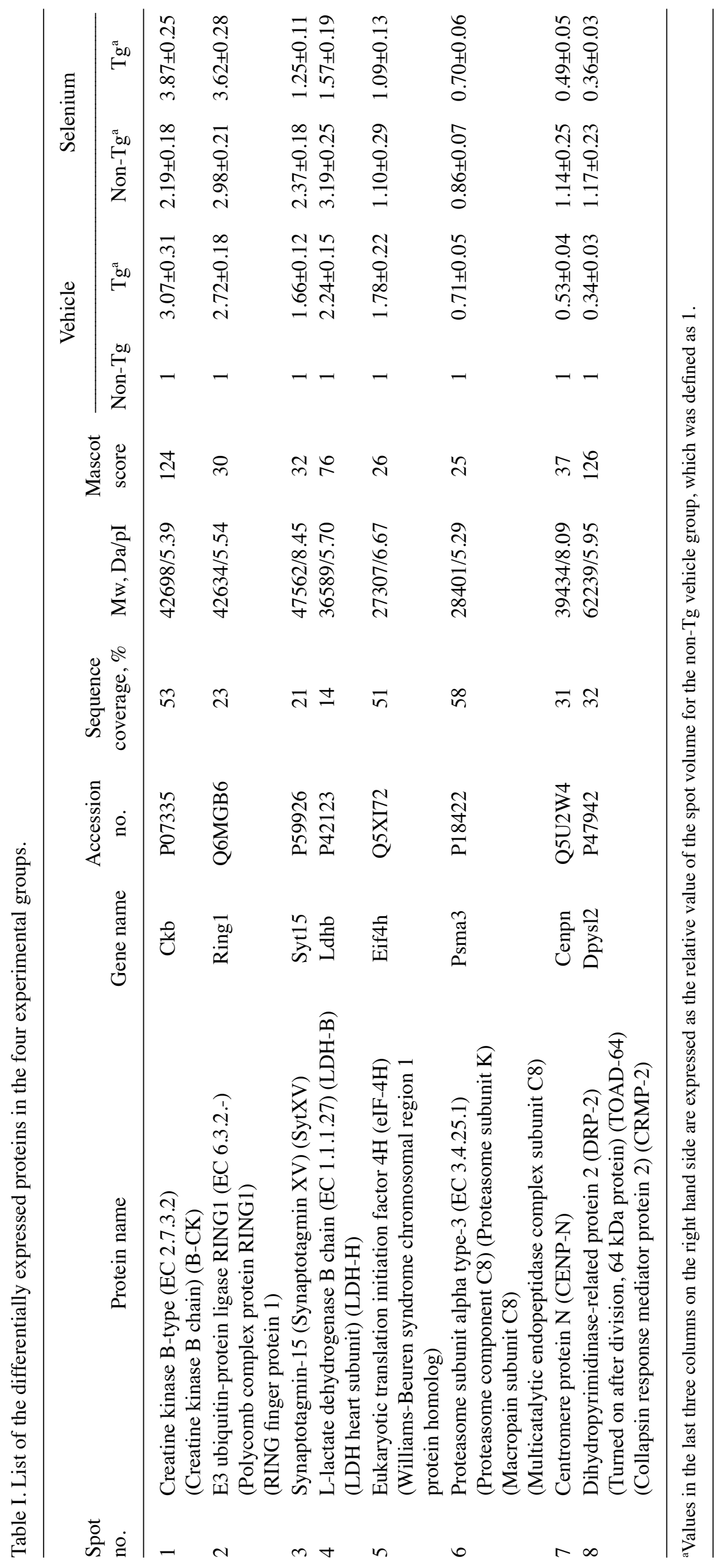




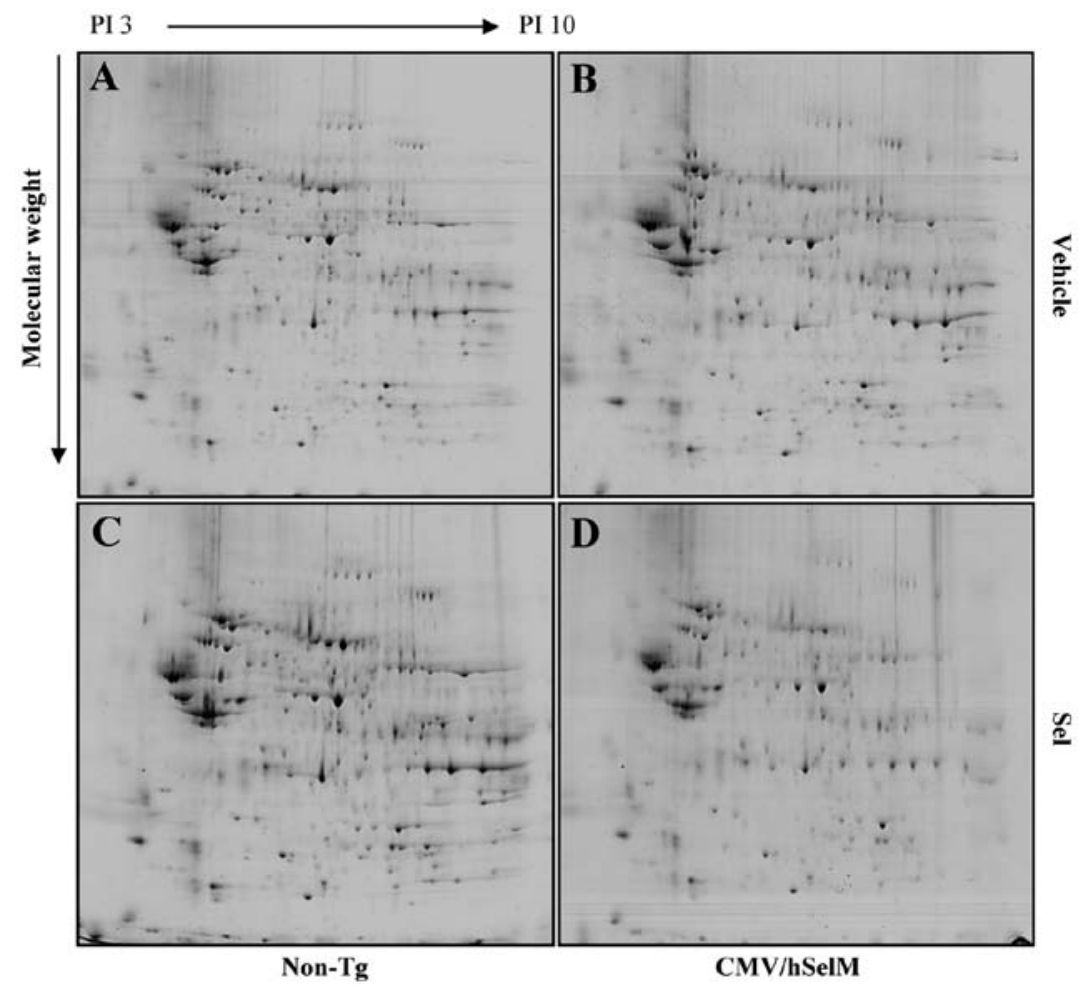

Figure 2. Two-dimensional electrophoresis (2-DE) protein patterns in the brain tissues from CMV/hSelM Tg and non-Tg rats. Analyses was of the brains cortex proteins by 2-DE. Cortex lysates (1 mg) from the rat brains of four groups; (A) vehicle-treated non-Tg, (B) selenium (Sel)-treated non-Tg, (C) vehicle-treated CMV/hSelM Tg and (D) Sel-treated CMV/hSelM Tg; were separated by one-dimensional isoelectric focusing (IEF) using $24 \mathrm{~cm}$ immobilized pH gradient strips with the $\mathrm{pH}$ range, 3.0-10.0 (non-linear). Second dimensional SDS-PAGE was then performed using 8-18\% linear gradient acrylamide gels in an EttanDalt system. Protein spots were visualized by Coomassie blue G-250 staining.

A

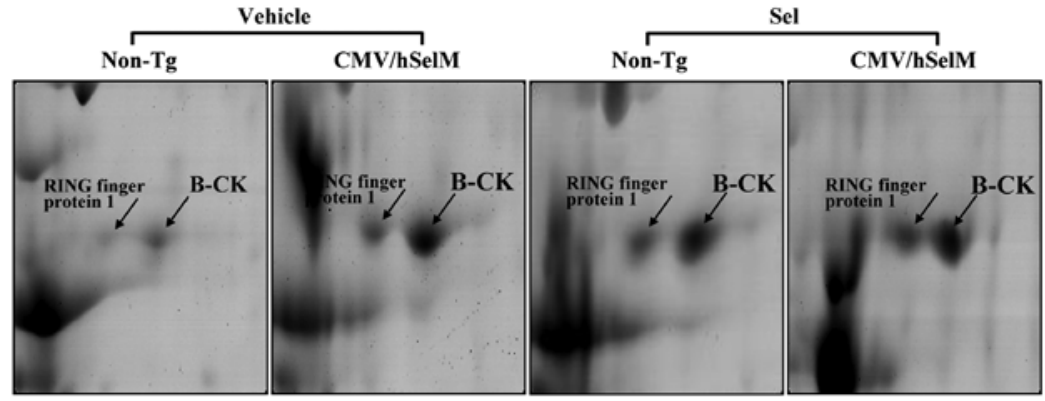

B
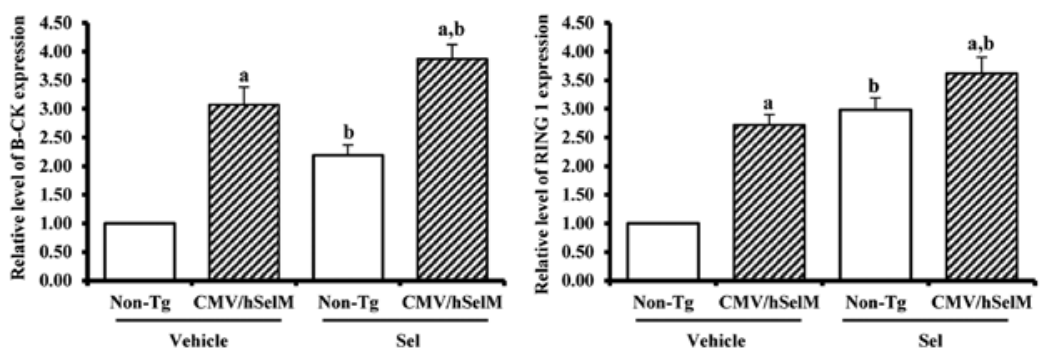

Figure 3. (A) Gel enlargement image and (B) relative expression level of RING finger protein 1 and creatine kinase B-type (B-CK) showing differential upregulation between cortex extracts from four experimental groups. Upregulated protein spots of RING finger protein 1 and B-CK were detected in the brain extracts from the four experimental groups. The spots differentially expressed on two-dimensional electrophoresis (2-DE) were further analyzed by a matrix-assisted laser desorption/ionization time-of-flight (MALDI-TOF) mass spectrometer. The data represent the means \pm standard deviation of three replicates. ${ }^{\text {aSignificant }}$ difference $(\mathrm{P}<0.05)$ when compared to non-Tg rats; ${ }^{\mathrm{b}}$ significant difference $(\mathrm{P}<0.05)$ when compared to the vehicle-treated group.

two spots increased in the Sel-treated group, they remained at a higher level in the $\mathrm{CMV} / \mathrm{hSelM} \mathrm{Tg}$ rats compared to the non-Tg rats (Fig. 3). The next group consisted of two spots that showed moderate changes in SytXV and LDH-B (Table I). The spot identified as SytXV was expressed at higher levels in the CMV/hSelM Tg rats than non-Tg rats that had received 
A

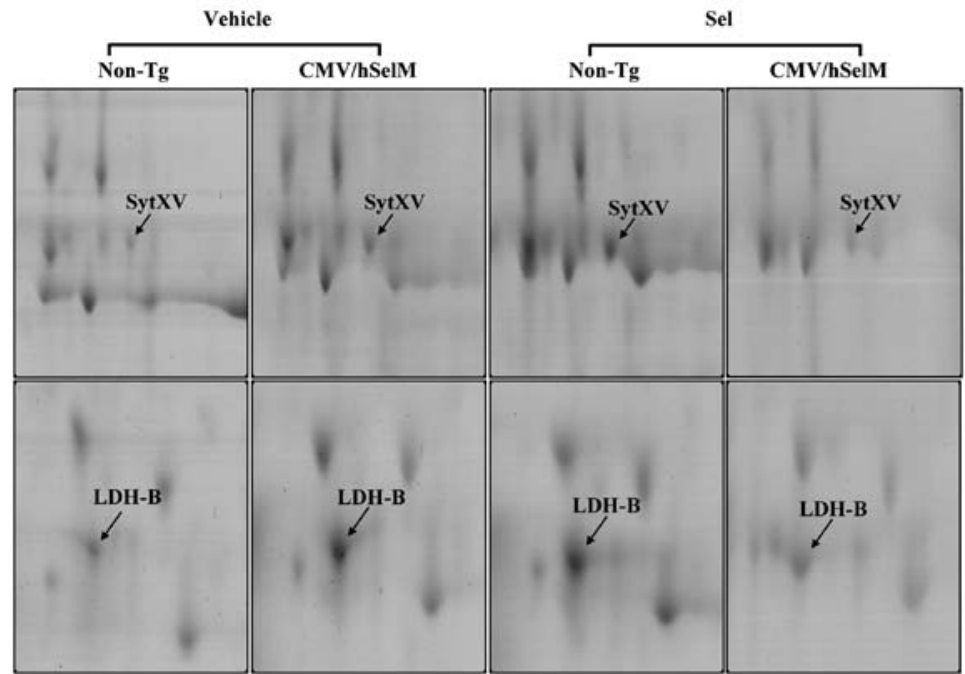

B
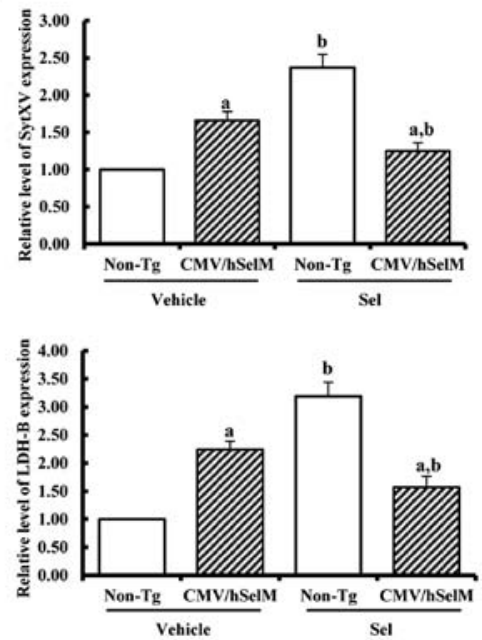

Figure 4. (A) Gel enlargement image and (B) relative expression level of synaptotagmin-15 (SytXV) and lactate dehydrogenase B (LDH-B) showing differential upregulation between cortex extracts from four experimental groups. Upregulated protein spots of SytXV and LDH-B were detected in the brain extracts from the four experimental groups. The spots differentially expressed on two-dimensional electrophoresis (2-DE) were further analyzed using a matrix-assisted laser desorption/ionization time-of-flight (MALDI-TOF) mass spectrometer. The data represent the means \pm standard deviation from three

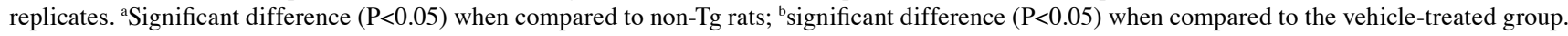

A

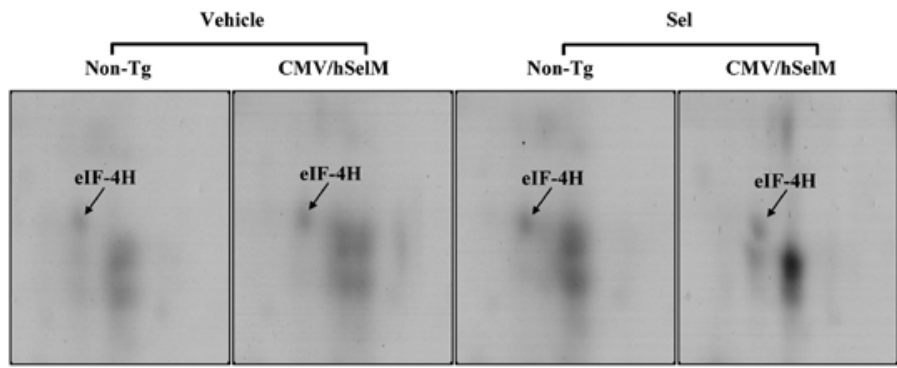

B

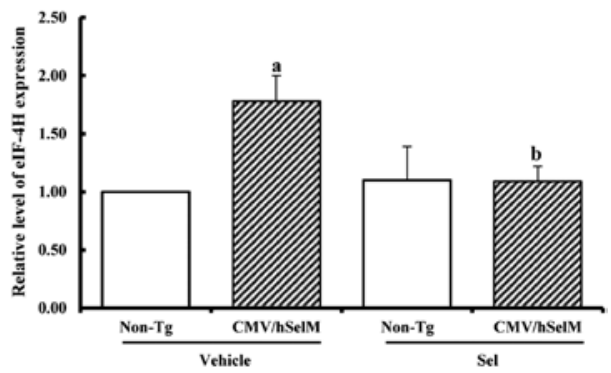

Figure 5. (A) Gel enlargement image and (B) relative expression level of eukaryotic translation initiation factor 4H (eIF-4H) showing differential up- or downregulation between cortex extracts from the four experimental groups. Up- or downregulated protein spots of eIF-4H were detected in the brain extracts from the four experimental groups. The spots differentially expressed on two-dimensional electrophoresis (2-DE) were further analyzed by a matrix-assisted laser desorption/ionization time-of-flight (MALDI-TOF) mass spectrometer. The data represent the means \pm standard deviation from three replicates. ${ }^{a}$ Significant difference $(\mathrm{P}<0.05)$ when compared to non-Tg rats; bignificant difference $(\mathrm{P}<0.05)$ when compared to the vehicle-treated group.

vehicle treatment. Sel treatment induced an increase in spot volume in non-Tg rats, whereas it was significantly decreased in CMV/hSelM Tg rats (Fig. 4). The spot isolated as LDH-B showed a change similar to the spot of SytXV. However, the basic level of these spots was higher in the CMV/hSelM Tg rats compared to the non-Tg rats (Fig. 4). The third group was not affected by Sel treatment and was only induced by SelM overexpression. Spot eIF-4H showed a significantly higher level in CMV/hSelM Tg rats, but was significantly downregulated following Sel treatment, whereas it remained unchanged in the non-Tg rats (Fig. 5).

The group that showed downregulated SelM was further classified into two subgroups. One large spot known as proteasome subunit $\mathrm{K}$ belonged to the first subgroup. The volume of this spot was lower in CMV/hSelM Tg rats than non- $\mathrm{Tg}$ rats under vehicle-treated conditions. However, Sel treatment induced a decrease in the proteasome subunit $\mathrm{K}$ level in non- $\mathrm{Tg}$ rats, whereas it remained at a constant level in the CMV/hSelM Tg rats (Fig. 6). In the second subgroup, two spots identified as CENP-N and DRP-2 showed similar patterns under the two conditions (Table I), with a lower level being observed for $\mathrm{CMV} / \mathrm{hSelM} \mathrm{Tg}$ rats than non-Tg rats. These levels were not changed following Sel treatment in either group (Fig. 7).

Confirmation of B-CK and SytXV expression. Western blot analysis was conducted to validate the changes in the protein expression levels of the two selected spots (B-CK and SytXV) identified by 2-DE. As shown in Fig. 8, the expression of $\mathrm{B}-\mathrm{CK}$ was significantly higher in the $\mathrm{CMV} / \mathrm{hSelM} \mathrm{Tg}$ rats than non-Tg rats. Following Sel treatment, its level increased further in the two groups, although its total expression pattern was maintained. In the case of SytXV, its expression level was higher in CMV/hSelM Tg rats compared to non-Tg rats under vehicle treatment conditions. However, expression of this protein increased significantly in response to Sel treatment in non-Tg rats, whereas CMV/hSelM rats showed no significant difference in expression. The expression pattern of the above proteins observed upon western blot analysis was extremely similar to that in the 2-DE gel image, indicating that the alteration of protein spots detected by 2 -DE reflects changes 
A

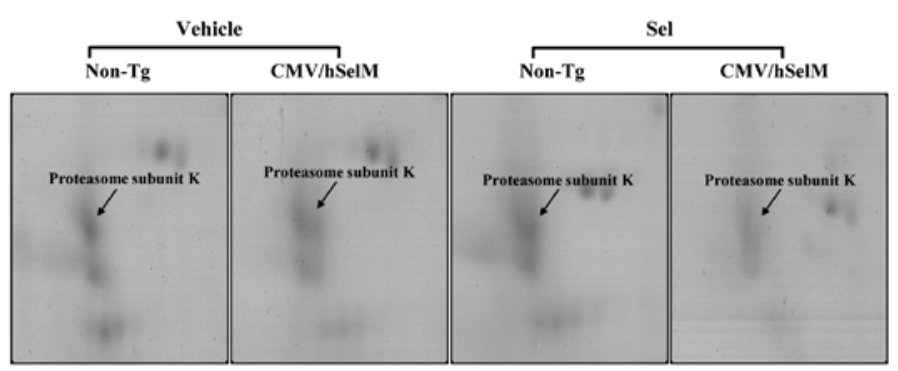

B

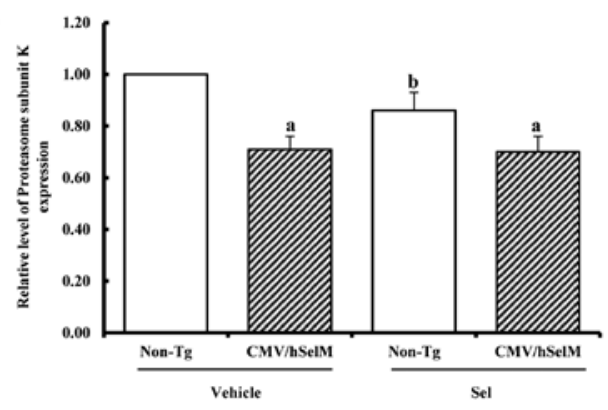

Figure 6. (A) Gel enlargement image and (B) relative expression level of proteasome subunit K showing differential downregulation between cortex extracts from four experimental groups. Downregulated protein spots of proteasome subunit $\mathrm{K}$ were detected in the brain extracts from the four experimental groups. The spots differentially expressed on two-dimensional electrophoresis (2-DE) were further analyzed by a matrix-assisted laser desorption/ionization time-of-flight (MALDI-TOF) mass spectrometer. The data represent the means \pm standard deviation from three replicates. ${ }^{a}$ Significant difference $(\mathrm{P}<0.05)$ when compared to non-Tg rats; ${ }^{b}$ significant difference $(\mathrm{P}<0.05)$ when compared to the vehicle-treated group.

A

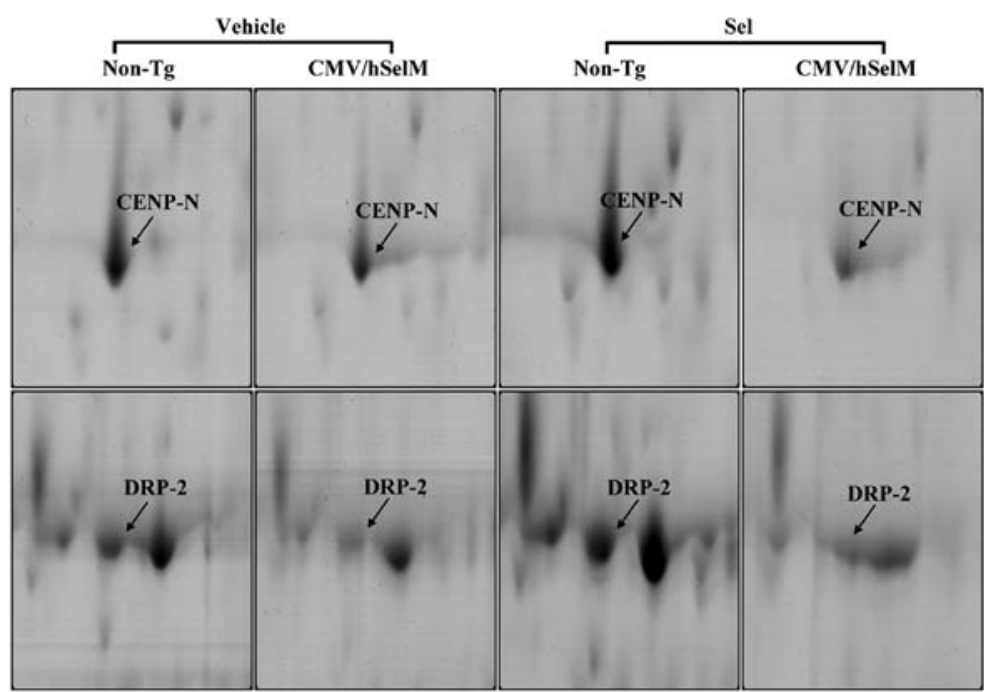

B

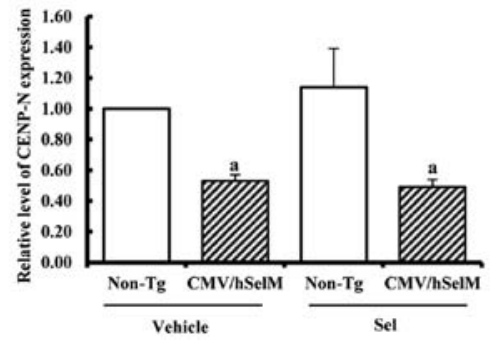

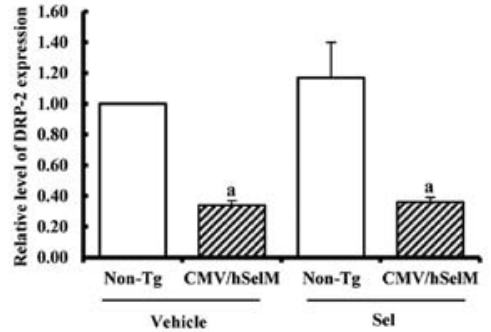

Figure 7. (A) Gel enlargement image and (B) relative expression level of CENP-N and DRP-2 showing differential downregulation between cortex extracts from four experimental groups. Downregulated protein spots of CENP-N and DRP-2 were detected in the brain extracts from the four experimental groups The spots differentially expressed on two-dimensional electrophoresis (2-DE) were further analyzed by a matrix-assisted laser desorption/ionization time-of-flight (MALDI-TOF) mass spectrometer. The data represent the means \pm standard deviation from three replicates. ${ }^{a}$ Significant difference $(\mathrm{P}<0.05)$ when compared to non-Tg rats. CENP-N, centromere protein N; DRP-2, dihydropyrimidinase-related protein 2.

in protein expression in the brains of the CMV/hSelM Tg and non-Tg rats.

\section{Discussion}

Sel deficiency is associated with a variety of serious diseases, including infectious disease, cardiovascular disease, cancer and neurodegenerative disorders (7). Savaskan et al (29) provided direct evidence that Sel plays a pivotal role in neuronal susceptibility to excitotoxic lesions. The results of this study indicated that the neuroprotective effects of Sel are not directly mediated via the antioxidative effects of selenite, but require de novo protein synthesis. Therefore, Sel deficiency in the brain tissue leads to increased oxidative stress with subsequent NK- $\kappa$ B activation and neuronal cell death. Several studies reported that intracellular ETKs were activated by either sodium selenite, an inorganic salt known to activate ERK (30), or transfected with a constitutively active mutant of MEK1, an immediate upstream activator of $\operatorname{ERKR}(31,32)$. The present study investigated whether the high level of 

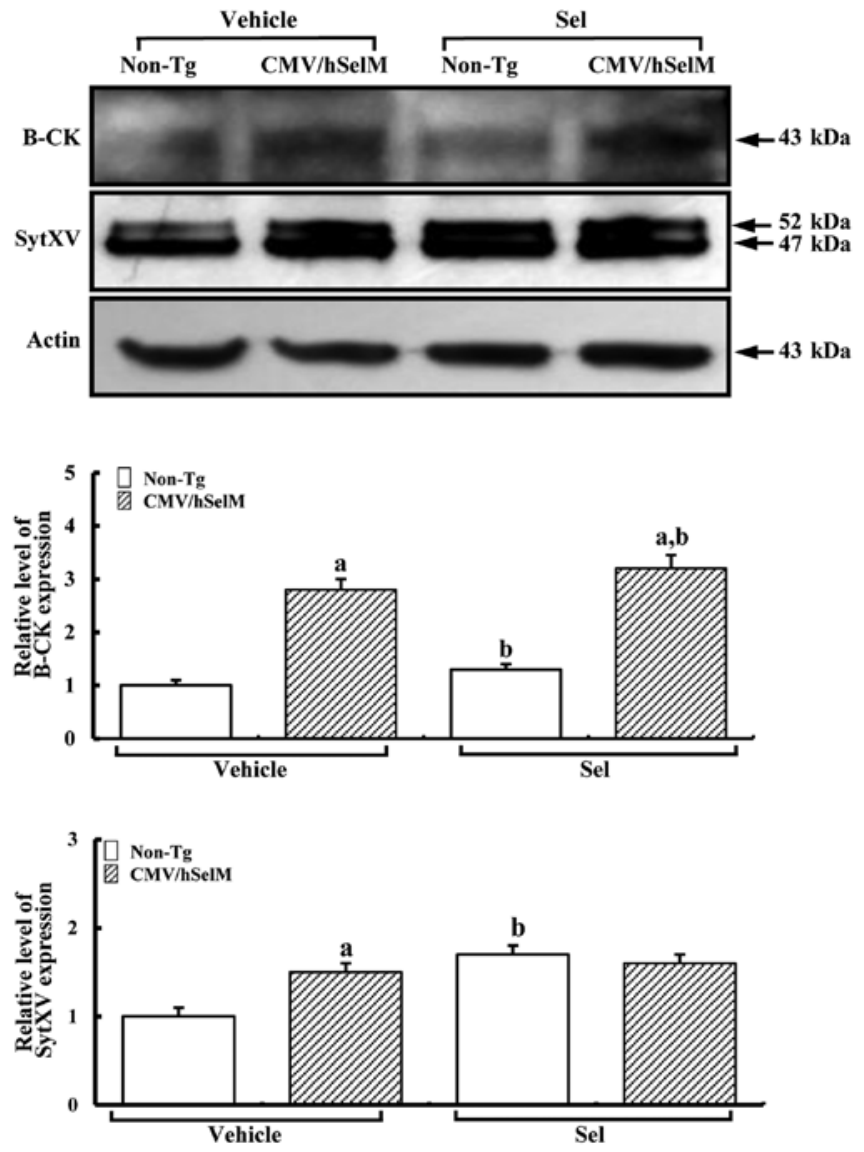

Figure 8. Conformation of creatine kinase B-type (B-CK) and synaptotagmin-15 (SytXV) expression in the brain cortex using western blot analysis. Tissue lysates were prepared from the brain tissue of vehicle-treated and selenium (Sel)-treated rats. Protein (50 $\mu \mathrm{g}$ per sample) were immunoblotted with the antibody for each protein. The expression level of B-CK and SytXV was detected with specific primary antibodies and horseradish peroxidase-conjugated goat anti-rabbit immunoglobulin $\mathrm{G}$ antibodies. The intensity of each protein was calculated using an imaging densitometer. The data represents the mean \pm standard deviation from three replicates. aSignificant difference $(\mathrm{P}<0.05)$ when compared to non-Tg rats; ${ }^{\text {b }}$ significant difference $(\mathrm{P}<0.05)$ when compared to the vehicle-treated group.

antioxidants induced by Sel treatment and SelM overexpression affected the change in the cortex proteins of CMV/hSelM $\mathrm{Tg}$ and non-Tg rats. The CMV/hSelM Tg rats used in the study showed a higher level of antioxidant enzymes, such as SOD and GPX, compared to non-Tg rats. Additionally, the concentration of total oxidized products regulated by these enzymes was significantly decreased in the brain cortex of the CMV/hSelM $\mathrm{Tg}$ rats compared to non- $\mathrm{Tg}$ rats. These results indicate that the antioxidant condition was induced by Sel treatment and SelM overexpression in CMV/hSelM Tg rats. Furthermore, these findings are concordant with those of our previous study (13).

$\mathrm{A} \beta-42$ peptide in the cortex of the brain is closely correlated with deposition at neuritic plaques in the pathogenesis of AD $(28,33)$. The production of these peptides is tightly regulated by $\gamma$-secretase, which is composed of presenilin and four additional cofactors, nicastrin, Aph-1, Pen-2 and TMP-21, to create a multimeric protease complex $(34,35)$. Thus far, limited studies investigating the correlation of Sel and $\gamma$-secretase have been conducted. The present study investigated whether the level of $\gamma$-secretase activity could be changed by Sel treatment and SelM overexpression in the brain of CMV/hSelM Tg rats. The results showed that the $\gamma$-secretase activity significantly decreased in response to Sel treatment. Therefore, the protein spot detected in the study may be correlated with the production of $\mathrm{A} \beta-42$ peptides in CMV/hSelM Tg rats.

The study identified eight spots that were differentially expressed among four groups, which were vehicle-treated non-Tg, vehicle-treated CMV/hSelM Tg, Sel-treated non-Tg and Sel-treated CMV/hSelM Tg rats. Among these spots, creatine kinase was significantly upregulated in response to Sel treatment and SelM overexpression. B-CK, one of the creatine kinases, catalyzed the conversion of creatine to phosphocreatine, which was expressed in various tissue types (36). Generally, this enzyme is known as a buffering system of cellular ATP concentration and used as a marker of several diseases, including myocardial infarction, rhabdomyolysis, muscular dystrophy and renal failure (37). Decreased creatine kinase activity was recently reported to be tightly associated with neurodegenerative pathways in neurodegenerative diseases (38), ischemia (39) and other diseases (40,41). Creatine kinase and pyruvate kinase are crucial for energy homeostasis and antioxidant defense through inhibition of two enzyme activities (42). In the present study, the expression of B-CK was higher in $\mathrm{CMV} / \mathrm{hSelM} \mathrm{Tg}$ rats overexpressing SelM protein than non-Tg rats under vehicle-treated conditions. In addition, Sel treatment induced an increase of this enzyme expression in the two groups. Furthermore, this change pattern was observed in the spot identified as RING1. This enzyme, which is known as a Parkin, appeared to be part of the cell's defense against damage caused by environmental insults (43). This enzyme ubiquitinates itself and promotes its own degradation, and the impairment of ubiquitin ligase function may cause familial autosomal recessive PD. Furthermore, oxidative and nitrosative stress were closely associated with the ubiquitin ligase function of PD and the associated $\alpha$-synucleinopathy (44).

SytXV and LDH-B showed similar protein change patterns on the 2-DE gels. Syt constitutes a family of membrane-trafficking proteins that are characterized by an N-terminal transmembrane region, a variable linker and two C-terminal domains $(45,46)$. This protein is known as a $\mathrm{Ca}^{2+}$ sensor that regulates $\mathrm{Ca}^{2+}$-dependent membrane trafficking, including endocrine exocytosis $(47,48)$, synaptic vesicle exocytosis $(49,50)$, plasma membrane repair $(51,52)$ and acrosomal reaction (53). Several studies have also documented the correlation between neurotransmitter release and Syt function $(54,55)$. However, limited studies of whether selenoprotein and Sel treatment were affected by SytXV expression have been conducted thus far. In the present study, the expression of this protein was significantly increased in response to SelM overexpression compared to non-Tg rats. However, in the CMV/hSelM Tg rats, Sel treatment did not induce a significant change in SytXV expression in the brain cortex. These results indicate that SelM overexpression could be affected by $\mathrm{Ca}^{2+}$-dependent membrane trafficking through the regulation of Syt expression. Another spot was identified as LDH-B, which catalyzes the interconversion of pyruvate and lactate with concomitant interconversion of NADH and $\mathrm{NAD}^{+}$(56). Nazam Ansari et al (57) showed that serum lactate dehydrogenase and GPX were significantly lower in rats with ischemia. However, in the present study, LDH-B was increased 
by SelM overexpression in CMV/hSelM Tg rats, but increased by Sel treatment in non-Tg rats, indicating that selenoprotein and Sel treatment are extremely important for normal brain function.

eIF-4H was the last member in the groups showing upregulated expression in response to SelM overexpression. This protein regulates protein synthesis through facilitating the binding of initiator tRNA to ribosomes (58). Several stress-responding genes induced by ultraviolet light, ER stress and reactive oxygen species were tightly regulated by eIF2. Furthermore, an abnormally high concentration of NO in the nervous system increases the eIF $2 \alpha$ level of phosphorylated forms, thus suppressing protein synthesis in neurons (59). The eIF $2 \alpha$ level of the phosphorylated form was also increased in hippocampal CA1 neurons following ischemia (60). In the present study, SelM overexpression induced increased eIF $2 \alpha$ expression, but Sel treatment did not induce any change in either group.

The expression of CENP-N was extremely similar to that of DRP-2 upon 2-DE analysis. CENP-N was first reported as a member of three new human centromere proteins (CENP-M, CENP-N and CENP-T), which comprised a CENP-A nucleosome-associated complex (CENP-A NAC) (61). Additionally, disruption of CENP-A NAC by reduction of these three proteins induced a mitotic defect or significant mitotic delay in cells. However, there have been no studies of the correlation between CENP-N and antioxidant status. Therefore, to the best of our knowledge, the present study is the first to indicate that SelM overexpression led to a significant decrease in the expression of CENP-N.

DRP-2 is turned on following division of the 64-kDa protein or collapsing response mediator protein 2 (CRMP-2). This protein is highly expressed in the adult brain, is an important molecule in neurite outgrowth and axonal guidance, and plays a role in several neurological diseases, including AD, epilepsy and ischemia $(62,63)$. Furthermore, a dramatic decrease of intact CRMP-2 was observed following maitotoxin treatment, $\mathrm{N}$-methyl-D-asparatate treatment and ischemia induction, accompanied by the appearance of distinct breakdown products of CRMP-2 (63). The present study showed that SelM overexpression led to significant induction of the decrease of DRP-2 in $\mathrm{CMV} / \mathrm{hSelM} \mathrm{Tg}$ rats compared to non-Tg rats. These results indicate that SelM could be referred to as a regulator of DRP-2, although further study of the degradation process is necessary.

All the aforementioned results showed that SelM overexpression and Sel treatment play a crucial role in the regulation of brain function via modulation of eight associated proteins. In addition, our proteomic analysis allowed the verification of the change in protein patterns of brain antioxidant regulation. However, intensive study is required to define the role and detailed mechanism of SelM and Sel in the cortex region of the brain.

\section{Acknowledgements}

The authors wish to acknowledge the animal technicians, S.M. Choi (BS) and Ms. J.L. Song, for directing the Animal Facility and Care at the Division of Laboratory Animal Resources. The present study was supported by the grants from the KFDA. This study was supported by the Bio and Medical
Technology Development Program of the National Research Foundation (NRF) funded by the Ministry of Science, ICT and Future Planning (2012M3A9B6055344), and also supported by Bio-industry Technology Development Program, Ministry of Agriculture, Food and Rural Affairs (311054-03-3-HD110) to Professor Je Kyung Seong.

\section{References}

1. Wilber CG: Toxicology of selenium: a review. Clin Toxicol 17: 171-230, 1980.

2. Smith AM and Picciano MF: Evidence for increased selenium requirement for the rat during pregnancy and lactation. J Nutr 116: 1068-1079, 1986.

3. Yang GQ, Chen JS, Wen ZM, Ge KY, Zhu LZ, Chen XC and Chen XS: The role of selenium in Keshan disease. Adv Nutr Res 6: 203-231, 1984.

4. van Rij AM, Thomson CD, McKenzie JM and Robinson MF: Selenium deficiency in total parenteral nutrition. Am J Clin Nutr 32: 2076-2085, 1979.

5. Schwarz K and Foltz CM: Selenium as an integral part of factor 3 against dietary necrotic liver degeneration. J Am Chem Soc 79: 3292-3293, 1957.

6. Reddy PG, Morill JL, Minocha HC and Stevenson JS: Vitamin E is immunostimulatory in calves. J Dairy Sci 70: 993-999, 1987.

7. Birringer M, Pilawa S and Flohé L: Trends in selenium biochemistry. Nat Prod Rep 19: 693-718, 2002.

8. Carlson BA, Novoselov SV, Kumaraswamy E, Lee BJ, Anver MR, Gladyshev VN and Hatfield DL: Specific excision of the selenocysteine tRNA[Ser]Sec (Trsp) gene in mouse liver demonstrates an essential role of selenoproteins in liver function. J Biol Chem 279: 8011-8017, 2004.

9. Berry MJ, Banu L, Chen YY, Mandel SJ, Kieffer JD, Harney JW and Larsen PR: Recognition of UGA as a selenocysteine codon in type I deiodinase requires sequences in the 3 ' untransalated region. Nature 353: 273-276, 1991.

10. Kryukov GV, Castellano S, Novoselov SV, Lobanov AV, Zehtab O, Guigó R and Gladyshev VN: Characterization of mammalian selenoproteomes. Science 300: 1439-1443, 2003.

11. Korotkov KV, Novoselov SV, Hatfield DL and Gladyshev VN: Mammalian selenoprotein in which selenocysteine (Sec) incorporation is supported by a new form of Sec insertion sequence element. Mol Cell Biol 22: 1402-1411, 2002.

12. Müller WE, Borejko A, Brandt D, et al: Selenium affects biosilica formation in the demosponge Suberites domuncula. Effect on gene expression and spicule formation. FEBS J 272: 3838-3852, 2005.

13. Hwang DY, Sin JS, Kim MS, et al: Overexpression of human selenoprotein $\mathrm{M}$ differentially regulates the concentrations of antioxidants and $\mathrm{H}_{2} \mathrm{O}_{2}$, the activity of antioxidant enzymes, and the composition of white blood cells in a transgenic rat. Int J Mol Med 21: 169-179, 2008.

14. Chen J and Berry MJ: Selenium and selenoproteins in the brain and brain diseases (Review). J Neurochem 86: 1-12, 2003.

15. Ramaekers VT, Calomme M, Vanden Berghe D and Makropoulos W: Selenium deficiency triggering intractable seizures. Neuropediatrics 25: 217-223, 1994.

16. Imam SZ, el-Yazal J, Newport GD, Itzhak Y, Cadet JL, Slikker W Jr and Ali SF: Methamphetamine-induced dopaminergic neurotoxicity: role of peroxynitrite and neuroprotective role of antioxidants and peroxynitrite decomposition catalysts. Ann NY Acad Sci 939: 366-380, 2001.

17. Zafar KS, Siddiqui A, Sayeed I, Ahmad M, Salim S and Islam F: Dose-dependent protective effect of selenium in rat model of Parkinson's disease: neurobehavioral and neurochemical evidences. J Neurochem 84: 438-446, 2003.

18. Takizawa S, Matsushima K, Shinohara Y, Ogawa S, Komatsu N, Utsunomiya $\mathrm{H}$ and Watanabe $\mathrm{K}$ : Immunohistochemical localization of glutathione peroxidase in infarcted human brain. J Neurol Sci 122: 66-73, 1994.

19. Saijoh K, Saito N, Lee MJ, Fujii M, Kobayashi T and Sumino K: Molecular cloning of cDNA encoding a bovine selenoprotein P-like protein containing 12 selenocysteines and a (His-Pro) rich domain insertion, and its regional expression. Brain Res Mol Brain Res 30: 301-311, 1995.

20. Kim IY, Shin JH and Seong JK: Mouse phenogenomics, toolbox for functional annotation of human genome. BMB Rep 43: 79-90, 2010 
21. Schomburg L, Schweizer U, Holtmann B, Flohé L, Sendtner M and Köhrle J: Gene disruption discloses role of selenoprotein $P$ in selenium delivery to target tissues. Biochem J 370: 397-402, 2003.

22. Hill KE, Zhou J,McMahan WJ, Motley AK, Atkins JF, Gesteland RF and Burk RF: Deletion of selenoprotein P alters distribution of selenium in the mouse. J Biol Chem 278: 13640-13646, 2003.

23. Hwang DY, Seo SJ, Kim YK, et al: Selenium acts as an insulin-like molecule for the downregulation of diabetic symptoms via endoplasmic reticulum stress and insulin signalling proteins in diabetes-induced non-obese diabetic mice. J Biosci 32 723-735, 2007.

24. Yim SY, Chae KR, Shim SB, et al: ERK activation induced by selenium treatment significantly downregulates beta/gamma-secretase activity and Tau phosphorylation in the transgenic rat overexpressing human selenoprotein $\mathrm{M}$. Int J Mol Med 24: 91-96, 2009.

25. Goo JS, Kim YN, Choi KM, et al: Proteomic analysis of kidneys from selenoprotein $M$ transgenic rats in response to increased bioability of selenium. Clin Proteomics 10: 10, 2013.

26. Park JY, Seong JK and Paik YK: Proteomic analysis of diet-induced hypercholesterolemic mice. Proteomics 4: 514-523, 2004.

27. Kim BH, Park EY, Yoo KH, Choi KM, Kim Y, Seong Jk and Park JH: N-myc downstream-regulated gene 1 is involved in the regulation of cystogenesis in transgenic mice overexpressing human PKD2 gene. Proteomics 13: 134-141, 2013.

28. Selkoe DJ: Alzheimer's disease: genes, proteins, and therapy. Physiol Rev 81: 741-766, 2001.

29. Savaskan NE, Bräuer AU, Kühbacher M, et al: Selenium deficiency increases susceptibility to glutamate-induced excitotoxicity. FASEB J 17: 112-114, 2003.

30. Hu H, Jiang C, Li G and Lü J: PKB/AKT and ERK regulation of caspase-mediated apoptosis by methylseleninic acid in LNCaP prostate cancer cells. Carcinogenesis 26: 1374-1381, 2005.

31. Jaaro H, Rubinfeld H, Hanoch $T$ and Seger R: Nuclear translocation of mitogen-activated protein kinase kinase (MEK1) in response to mitogenic stimulation. Proc Natl Acad Sci USA 94: 3742-3747, 1997.

32. Seger R, Seger D, Reszka AA, et al: Overexpression of mitogen-activated protein kinase kinase (MAPKK) and its mutants in NIH 3T3 cells. Evidence that MAPKK involvement in cellular proliferation is regulated by phosphorylation of serine residues in its kinase subdomains VII and VIII. J Biol Chem 269: 25699-25709, 1994.

33. Kim SK, Park HJ, Hong HS, Baik EJ, Jung MW and Mook-Jung I: ERK1/2 is an endogenous negative regulator of the gamma-secretase activity. FASEB J 20: 157-159, 2006.

34. Iwatsubo T: The gamma-secretase complex: machinery for intramembrane proteolysis. Curr Opin Neurobiol 14: 379-383, 2004.

35. Chen F, Hasegawa H, Schmitt-Ulms G, et al: TMP 21 is a presenilin complex component that modulates gamma-secretase but not epsilon-secretase activity. Nature 440: 1208-1212, 2006.

36. Bessman SP and Carpenter CL: The creatine-creatine phosphate energy shuttle. Annu Rev Biochem 54: 831-862, 1985.

37. Schnyder T, Winkler H, Gross H, Eppenberger HM and Wallimann T: Crystallization of mitochondrial creatine kinase. Growing of large protein crystals and electron microscopic investigation of microcrystals consisting of octamers. J Biol Chem 266: 5318-5322, 1991.

38. David S, Shoemaker M and Haley BE: Abnormal properties of creatine kinase in Alzheimer's disease brain: correlation of reduced enzyme activity and active site photolabeling with aberrant cytosol-membrane partitioning. Brain Res Mol Brain Res 54: 276-287, 1998.

39. Tomimoto H, Yamamoto K, Homburger HA and Yanagihara T: Immunoelectron microscopic investigation of creatine kinase BB-isoenzyme after cerebral ischemia in gerbils. Acta Neuropathol 86: 447-455, 1993.

40. Gross WL, Bak MI, Ingwall JS, Arstall MA, Smith TW, Balligand JL and Kelly RA: Nitric oxide inhibits creatine kinase and regulates rat heart contractile reserve. Proc Natl Acad Sci USA 93: 5604-5609, 1996.

41. Hamman BL, Bittl JA, Jacobus WE, Allen PD, Spencer RS, Tian R and Ingwall JS: Inhibition of the creatine kinase reaction decreases the contractile reserve of isolated rat hearts. Am J Physiol 269: H1030-H1036, 1995.

42. Rech VC, Feksa LR, Fleck RM, Athaydes GA, Dornelles PK, Rodrigues-Junior V and Wannmacher CM: Cysteamine prevents inhibition of thiol-containing enzymes caused by cystine or cystine dimethylester loading in rat brain cortex. Metab Brain Dis 23: 133-145, 2008
43. Steece-Collier K, Maries E and Kordower JH: Etiology of Parkinson's disease: genetics and environment revisited. Proc Natl Acad Sci USA 99: 13972-13974, 2002.

44. Dawson TM: Parkin and defective ubiquitination in Parkinson's disease. J Neural Transm Suppl 70: 209-213, 2006

45. Fukuda M and Mikoshiba K: Synaptotagmin-like protein 1-3: a novel family of C-terminal-type tandem $\mathrm{C} 2$ proteins. Biochem Biophys Res Commun 281: 1226-1233, 2001.

46. Fukuda M, Saegusa C and Mikoshiba K: Novel splicing isoforms of synaptotagmin-like proteins 2 and 3: identification of the Slp homology domain. Biochem Biophys Res Commun 283: 513-519, 2001.

47. Sugita S, Shin OH, Han W, Lao Y and Südhof TC: Synaptotagmins form a hierarchy of exocytotic $\mathrm{Ca}(2+)$ sensors with distinct $\mathrm{Ca}(2+)$ affinities. EMBO J 21: 270-280, 2002

48. Fukuda M, Kanno E, Ogata Y, Saegusa C, Kim T, Loh YP and Yamamoto A: Nerve growth factor-dependent sorting of synaptotagmin IV protein to mature dense-core vesicles that undergo calcium-dependent exocytosis in PC12 cells. J Biol Chem 278: 3220-3226, 2003

49. Chapman ER: Synaptotagmin: a $\mathrm{Ca}(2+)$ sensor that triggers exocytosis? Nat Rev Mol Cell Biol 3: 498-508, 2002.

50. Mikoshiba K, Fukuda M, Moreira JE, Lewis FMT, Sugimori M, Niinobe $\mathrm{M}$ and Llinás R: Role of the $\mathrm{C} 2 \mathrm{~A}$ domain of synaptotagmin in transmitter release as determined by specific antibody injection into the squid giant synapse preterminal. Proc Natl Acad Sci USA 92: 10703-10707, 1995.

51. Detrait ER, Yoo S, Eddleman CS, Fukuda M, Bittner GD and Fishman HM: Plasmalemmal repair of severed neurites of PC12 cells requires $\mathrm{Ca}(2+)$ and synaptotagmin. J Neurosci Res 62: 566-573, 2000

52. Reddy A, Caler EV and Andrews NW: Plasma membrane repair is mediated by $\mathrm{Ca}(2+)$-regulated exocytosis of lysosomes. Cell 106: 157-169, 2001.

53. Michaut M, De Blas G, Tomes CN, Yunes R, Fukuda M and Mayorga LS: Synaptotagmin VI participates in the acrosome reaction of human spermatozoa. Dev Biol 235: 521-529, 2001.

54. Schiavo G, Osborne SL and Sgouros JG: Synaptotagmins: more isoforms than functions? Biochem Biophys Res Commun 248: $1-8,1998$.

55. Fukuda M and Mikoshiba K: The function of inositol high polyphosphate binding proteins. Bioessays 19: 593-603, 1997.

56. Philibert RA, Nelson JJ, Sandhu HK, Crowe RR and Coryell WH: Association of an exonic LDHA polymorphism with altered respiratory response in probands at high risk for panic disorder. Am J Med Genet B Neuropsychiatr Genet 117: 11-17, 2003.

57. Nazam Ansari M, Bhandari U, Islam F, Tripathi CD: Evaluation of antioxidant and neuroprotective effect of ethanolic extract of Embelia ribes Burm in focal cerebral ischemia/reperfusion-induced oxidative stress in rats. Fundam Clin Pharmacol 22: 305-314, 2008.

58. Kim HS, Choi Y, Shin KY, et al: Swedish amyloid precursor protein mutation increases phosphorylation of eIF2alpha in vitro and in vivo. J Neurosci Res 85: 1528-1537, 2007.

59. Petrov T, Underwood BD, Braun B, Alousi SS and Rafols JA: Upregulation of iNOS expression and phosphorylation of eIF-2alpha are paralleled by suppression of protein synthesis in rat hypothalamus in a closed head trauma model. J Neurotrauma 18: 799-812, 2001

60. Hayashi T, Saito A, Okuno S, et al: Oxidative damage to the endoplasmic reticulum is implicated in ischemic neuronal cell death. J Cereb Blood Flow Metab 23: 1117-1128, 2003.

61. Foltz DR, Jansen LE, Black BE, Bailey AO, Yates JR 3rd and Cleveland DW: The human CENP-A centromeric nucleosome-associated complex. Nat Cell Biol 8: 458-469, 2006.

62. Zhang Z, Ottens AK, Sadasivan S, Kobeissy FH, Fang T, Hayes RL and Wang KK: Calpain-mediated collapsin response mediator protein-1, -2 , and -4 proteolysis after neurotoxic and traumatic brain injury. J Neurotrauma 24: 460-472, 2007.

63. Chung MA, Lee JE, Lee JY, Ko MJ, Lee ST and Kim HJ: Alteration of collapsin response mediator protein-2 expression in focal ischemic rat brain. Neuroreport 16: 1647-1653, 2005. 